\title{
Recuperación de la Casa del Pulimento en la Real Fábrica de Cristales de La Granja (Segovia). Estudios previos
}

\section{Sonia Fernández ${ }^{\mathrm{a}}$, Amparo Martín ${ }^{\mathrm{a}}$, Paloma Pastor ${ }^{\mathrm{b}}$ y María Jesús Callejo ${ }^{\mathrm{c}}$}

${ }^{a}$ GROMA, Estudio de Arqueología y Patrimonio, Urb. El Parque, 11, 40100 La Granja, Segovia. groma.arqueologia@gmail.com, ${ }^{\mathrm{b}}$ Fundación del Sector Público Centro Nacional del Vidrio, Paseo del Pocillo, 1, 40100 La Granja, Segovia, paloma.pastor@realfabricadecristales.es, ${ }^{\mathrm{c} E s c u e l a ~ T e ́ c n i c a ~ S u p e r i o r ~ d e ~ A r q u i t e c t u r a, ~ U n i v e r s i d a d ~ P o l i t e ́ c n t i c a ~ d e ~ M a d r i d, ~ C a l l e ~}$ Carretas nº 13, 40001-Segovia, mariajesus.callejo@upm.es.

\section{Resumen}

Al hilo de los avances tecnológicos en las manufacturas del vidrio durante el siglo XVIII, el ingeniero Juan Dowling diseñó en la Real Fábrica de Cristales de La Granja una nueva máquina hidráulica que permitía pulir cristales planos para producir lunas de espejo. Para albergar la máquina se construyó a las afueras del núcleo urbano una instalación que contaba con una edificación (Casa del Pulimento) y un sistema hidráulico que le proporcionaba la fuerza motriz.

Este nuevo ingenio supuso un hito tecnológico e incluso fue presentado en la Encyclopédie de Diderot y d'Alambert. Tras unos decenios en funcionamiento fue abandonado y en la actualidad únicamente queda en pie parte de su edificación.

Se ha abordado un proyecto de recuperación promovido por el Ayuntamiento de La Granja para el estudio, protección y difusión de la Casa del Pulimento, tanto de las estructuras emergentes que aún se conservan como del funcionamiento de la máquina y del sistema hidráulico del que obtenía la fuerza motriz. En esta comunicación se presentan los resultados de los estudios previos que han consistido en el análisis arquitectónico de las estructuras emergentes, en una prospección arqueológica y en el estudio documental de las noticias conservadas en diversos archivos.

Palabras clave: manufacturas reales, arqueología industrial, industria del vidrio, historia de la ingeniería.

\begin{abstract}
:
Linked to the technological advances developed in the $18^{\text {th }}$ century in the Royal Glass Factory of La Granja, the engineer Juan Dowling designed a new water machine able to polish flat glass for mirrors. To house the machine, a facility was built just outside the town centre. It had a building and a hydraulic system for providing the driving force.

The new machine meant a remarkable technological achievement that was even published at the Encyclopédie by Diderot and d'Alambert. After some decades working, the plant was abandoned and currently just a part of the building remains standing.

A project promoted by the La Granja Council is being carried out, in order to study, protect and publish La Casa del Pulimento, not only its remaining walls but also the working machine and the water system that provided the driving force. In this paper the results of the preliminary works are presented involving architectonical analysis and archaeological research along with desk study of the archival sources.
\end{abstract}

Keywords: royal manufacturing, industrial archaeology, glass making, history of engineering. 


\section{Introducción}

En el extremo nororiental del municipio San Ildefonso, junto a la margen derecha del río Cambrones y en un área cercana al núcleo urbano se encuentran los restos de la Casa del Pulimento (Fig. 1), una antigua instalación construida en el siglo XVIII para albergar un ingenio innovador que daba servicio a la Real Fábrica de Cristales de La Granja.

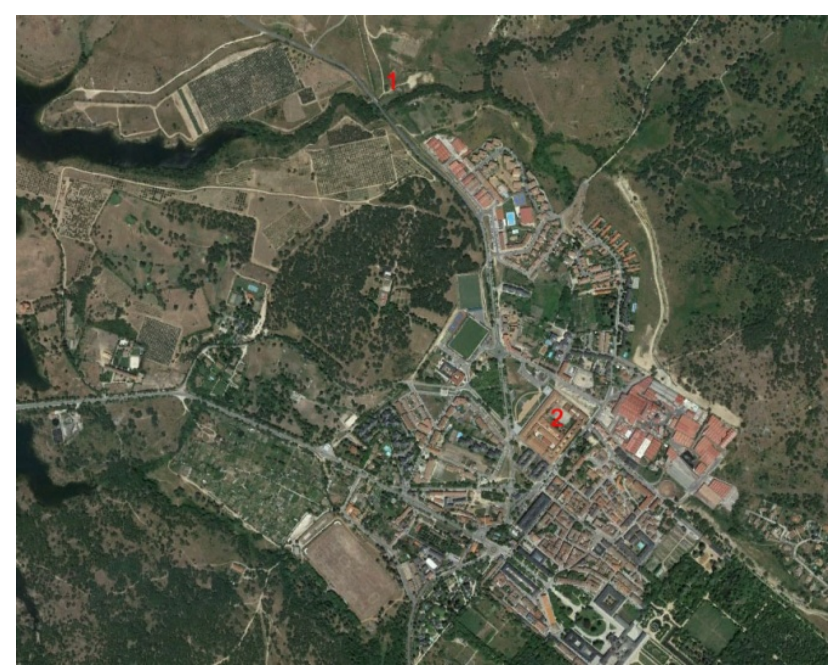

Fig. 1 Vista aérea del núcleo de La Granja con ubicación de la Casa del Pulimento (1) y la Real Fábrica de Cristales (2)

Aunque se han dedicado considerables esfuerzos al estudio de la Real Fábrica de Cristales de La Granja, y ésta ha sido objeto de documentados estudios que han permitido conocer con bastante precisión su evolución, los sistemas de producción empleados, la organización del trabajo y la tipología formal de las piezas producidas a lo largo de su historia (Pastor, 1994; 1997; 1998; 2004; Ruiz y Callejo, 1988), lo cierto es que la Casa del Pulimento no ha gozado de la misma suerte: pese a constituir un destacado testimonio de las innovaciones tecnológicas en las industrias del siglo XVIII, su memoria está prácticamente olvidada, apenas cuenta con noticias bibliográficas (Pastor, 1994; Juárez, 2016; Soler, 2014) y sus restos materiales se encuentran en un comprometido estado de conservación.

Para paliar esta situación el Ayuntamiento del Real Sitio de San Ildefonso junto con la Asociación Tecnológica de Amigos del Vidrio de La Granja ha promovido un proyecto de recuperación y valorización de la Casa del Pulimento que en la actualidad se encuentra en fase de estudios previos de los que se presenta un sucinto resumen en esta comunicación.

\section{La Real Fábrica de Cristales y las labores de raspamento y pulimento para las lunas destinadas a espejos}

La llegada de la monarquía borbónica a España supuso un momento clave en el desarrollo tecnológico del país. El Estado español protegió y fomentó la industria nacional con el deseo de intentar frenar el elevado índice de importaciones. Invirtió así cuantiosas sumas destinadas no sólo a la incorporación de personal especializado extranjero, sino también a la adquisición de la tecnología más avanzada del momento y a su costoso mantenimiento.

Los primeros indicios de mecanización aplicada al vidrio en España se desarrollaron en la Real Fábrica de Cristales de La Granja en el siglo XVIII, con la incorporación de máquinas hidráulicas accionadas por una gran rueda o noria giratoria que daba movimiento a un telar de pulidores o raspadores para desbastar las lunas de vidrio que iban destinadas a espejos.

Desde los orígenes, el raspado y el pulido de lunas se realizó siempre en la Real Fábrica de Cristales, a mano, una tarea lenta y laboriosa que exigía el trabajo de un buen número de operarios durante largas horas. Para agilizar estos trabajos y disminuir los elevados costes de manufacturación, se idearon unas máquinas hidráulicas que, con el tiempo, fueron perfeccionándose, hasta alcanzar, a finales del siglo XVIII y principios del XIX, los niveles óptimos de rendimiento y rentabilidad. 
La realización de estos ingenios hidráulicos exigía una gran precisión a la hora de controlar, de forma armónica, los distintos movimientos de fricción de los pulidores o raspadores. Los inventores de estas máquinas solían ser ingenieros y el cuidado diario era atendido por capataces y ayudantes, quienes cuidaban del normal funcionamiento y de la supervisión del trabajo de los operarios, encargados de levantar los pulidores o raspadores para colocar las lunas en los bancos respectivos, repartir las arenas o esmeriles, mezclados con agua y, finalmente, retirar las lunas ya desbastadas.

Aunque estuvieron en funcionamiento durante el siglo XVIII varias máquinas hidráulicas de raspamento y pulimento en el Real Sitio para dar servicio a la fábrica, hubo una que por su complejidad y su efectividad sobresalió entre las demás, nos referimos a la máquina del pulimento que diseña en la década de los 60 el ingeniero hidráulico Juan Dowling, próxima al arroyo Cambrones del Real Sitio y que pasamos a estudiar a continuación.

\subsection{La máquina del pulimento de Dowling}

El sencillo hecho de que sirviera como modelo en la Encyclopédie es muy significativo de la popularidad de que gozaba, debida a lo ingenioso del artefacto y a su perfección: "Consistía éste en una máquina de madera, con una rueda hidráulica, que ocupaba una superficie de $11 \times 12 \mathrm{~m}$ en el centro de la nave. Un caz tomaba el agua del arroyo Cambrones para mover el artilugio. El agua hacía girar una enorme rueda de cangilones, metida en un foso, a los extremos de cuyo eje unas ruedas dentadas, de menor diámetro, transmitían el movimiento a otras más pequeñas aún, de engranajes, cuyas manivelas producían un movimiento lateral en un chasis provisto de dieciséis pulidores, colocados sobre una mesa de piedra que contorneaba el foso. Los vidrios que se iban a pulir se ponían sobre esta mesa y un curiso dispositivo de transmisión de fuerzas permitía realizar la misma operación en el piso alto, duplicando de esta manera la producción" (Ruiz y Callejo, 1988, pp. 41-42) (Fig. 2).
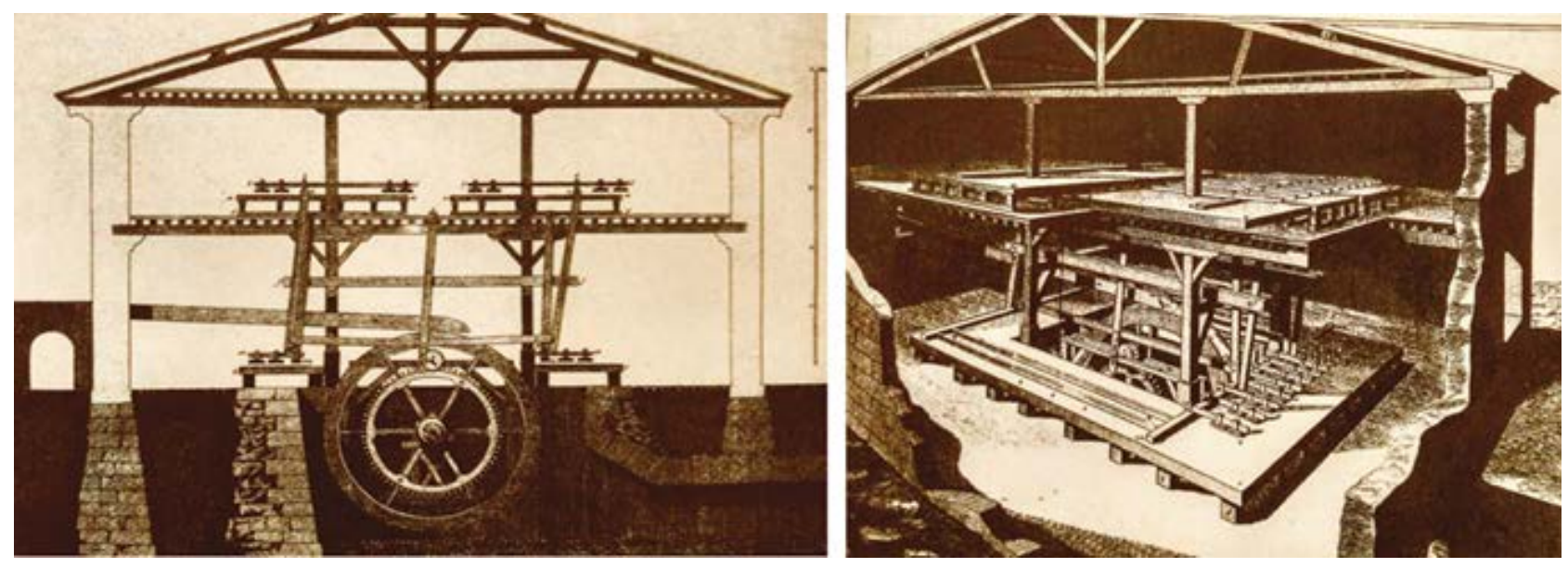

Fuente: Encyclopédie de Diderot y D’Alembert

Fig. 2 Máquina de J. Dowling

Poco tiempo después de su construcción, el día 8 de abril de 1763, la máquina comenzó a pulir vidrios planos con 32 pulidores que componían el cuerpo de arriba o segundos pulidores; el cuerpo inferior, o primeros pulidores, se pondrían en funcionamiento en breve. Según el director Bernardo Ward la máquina podía activar hasta 100 pulidores a un mismo tiempo, aunque con el funcionamiento de la tercera parte de pulidores era suficiente para el volumen de trabajo que había en ese momento, lo que ahorraba tiempo y salarios, pues el trabajo de cada pulidor equivalía a la labor de dos hombres.

Los trabajos de la casa y la máquina terminaron el 24 de Julio de 1764, según el resumen general de cuentas que el contador de la Real Fábrica Diego Navarro emite el 15 de marzo de 1765. Según este resumen de gastos redactado por la contaduría, la obra y construcción de la máquina de pulir cristales de Dowling supuso un gasto total de 256.882 reales de vellón y 18 maravedíes. 


\section{Objetivos}

En el momento actual el edificio de la Casa del Pulimento donde se encontraba la máquina de Dowling se encuentra en estado de abandono y mantiene únicamente los muros perimetrales (Fig. 3). Además, se ha perdido cualquier huella material en superficie del sistema hidráulico necesario para accionar la máquina. Así pues, auspiciado por el Ayuntamiento de La Granja, se ha iniciado un proyecto que pretende constituirse en un conjunto de acciones organizadas en fases sucesivas que a la luz de los resultados producidos en cada una de ellas, se vayan diseñando los objetivos específicos de la siguiente, todo ello con el objetivo final de protección, recuperación y puesta en valor de este elemento patrimonial de considerable entidad, testimonio material de un hito en los avances tecnológicos del siglo XVIII.

El proyecto se ha iniciado con una fase de estudios previos dirigida a conocer desde el punto de vista histórico la Casa del Pulimento y a valorar los elementos materiales que aún se conservan así como para dotarlo de un situación administrativa que permita su protección legal.

De este modo, el trabajo se ha desarrollado en tres líneas de actuación, la primera de ellas, llevada a cabo por el arquitecto José Mata Wagner, ha consistido en el análisis de patologías de las estructuras emergentes conservadas con el objetivo de diseñar un proyecto de actuación dirigido a paliar el deterioro e intentar detener el proceso de ruina del edificio.

Otra de las líneas de actuación ha consistido en el análisis con metodología arqueológica de los restos conservados para intentar determinar la extensión completa del complejo que incluye no solo la edificación, sino también el sistema hidráulico asociado. Para ello se ha realizado una primera aproximación arqueológica al edificio y una prospección de superficie del entorno, cuyos resultados han servido para solicitar a la Junta de Castilla y León la inclusión de este bien y sus elementos asociados en el Inventario Arqueológico de Castilla y León como primer paso para su protección legal ${ }^{1}$.

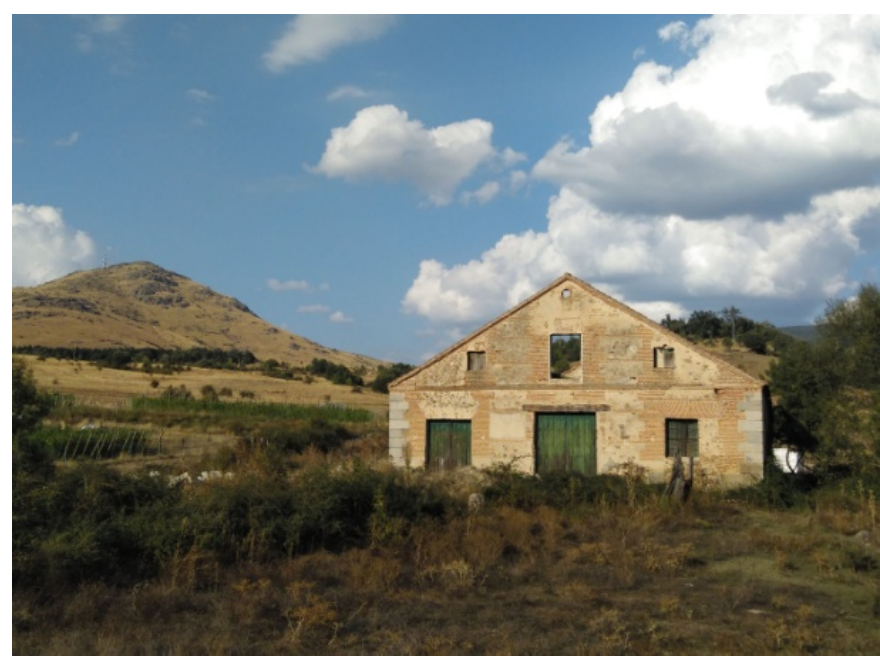

Fig. 3 Vista general del edificio

Pero la línea de actuación que ha proporcionado un elenco más rico de datos ha sido el estudio documental. A través del análisis de las noticias recogidas principalmente en el Archivo General de Palacio pero también en los archivos históricos del Ayuntamiento de San Ildefonso y provincial de Segovia así como en el Registro de la Propiedad $\mathrm{n}^{\circ} 3$ de Segovia, se ha obtenido una información sustancial sobre la construcción del edificio, el funcionamiento de la máquina o los problemas relacionados con la captación de agua, así como sobre el abandono de la instalación fabril y su devenir posterior.

\footnotetext{
${ }^{1}$ El Inventario Arqueológico de Castilla y León es la principal herramienta de protección: "el inventario arqueológico es la base para la acción normativa, pero también el repositorio de datos que constituye la fuente primordial para la investigación científica y la participación ciudadana" ORDEN CYT/475/2018. BOCyL 9-05-2018.
} 


\section{Resultados}

\subsection{Estudio Arqueológico}

Se ha realizado una primera caracterización de los restos que en la actualidad quedan de la Casa del Pulimento constituida por un edificio de planta cuadrangular de $22 \times 17 \mathrm{~m}$ y cubierta a dos aguas. Está construido en fábrica mixta de cajones de mampostería delimitados por paramentos de ladrillos macizos dispuestos a soga y tizón, mientras que las esquinas están rematadas por piezas de sillería granítica dispuestas en cremallera. La cornisa es de ladrillo y sobre ella descansaba hasta hace 2 años la cubierta a dos aguas con amplios faldones sobre un armazón de madera. Todas los muros muestran huellas de las transformaciones que ha sufrido el edificio con posterioridad a su uso como Casa del Pulimento aunque es la fachada occidental la que se encuentra más modificada. En ella se sitúa el acceso al interior, un gran vano cuadrangular en cuyo dintel una viga cargadero revela la siguiente inscripción "Año G.M. 1891" y a ambos lados se disponen otros dos vanos enmarcados por paramentos de ladrillo, mientras que en la planta bajo rasante existen otras tres ventanas. En el resto de los muros se suceden los vanos de similares características excepto uno, hoy cegado, situado en la parte superior de la fachada norte próximo a la línea de imposta, de tendencia circular y pequeñas dimensiones que podría corresponderse con el paso del agua al interior del edificio para proporcionar la fuerza motriz (Fig. 4). En la actualidad el interior del edificio se encuentra completamente desmantelado.

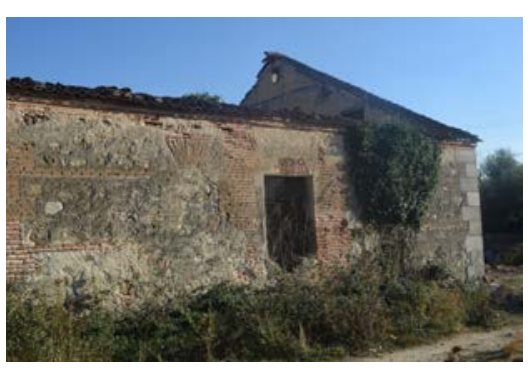

Fig. 4 Fachada norte del edificio
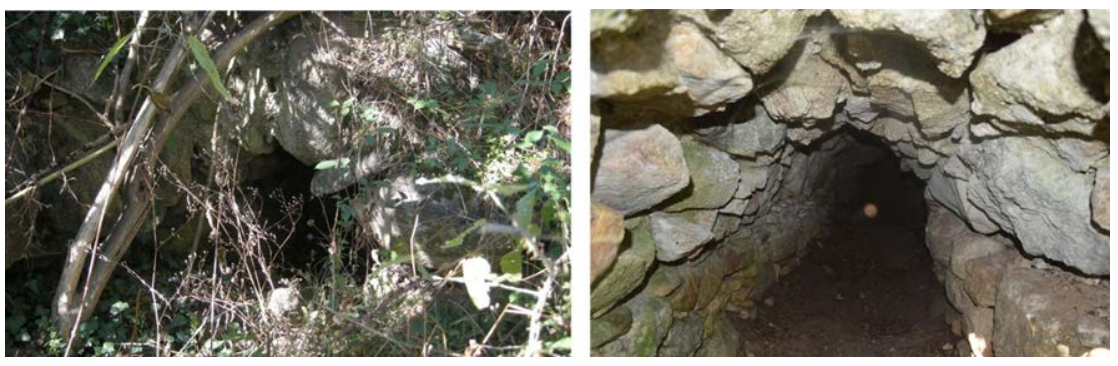

Fig. 5 Vistas exterior e interior del socaz

Con el objeto de identificar cualquier elemento asociado al sistema hidráulico de la Casa del Pulimento se ha realizado también una prospección arqueológica de superficie de carácter intensivo en un espacio de 16 ha en torno al edificio y a los dos cursos de agua más cercanos. Estos trabajos han servido para documentar el sistema de desagüe de la Casa del Pulimento con el hallazgo de una canalización soterrada de $80 \mathrm{~cm}$ de anchura y una altura vista de $86 \mathrm{~cm}$ construida con piezas de granito sin trabajar (Fig. 5). Esta estructura únicamente resulta visible en su extremo final junto al río Cambrones.

Los resultados de la prospección no han permitido localizar ningún resto material relacionado con el lugar exacto de la captación del agua, el trazado del caz o la existencia de la presumible balsa cercana al edificio que serviría para regular el flujo continuo necesario en el funcionamiento de la rueda hidráulica. A excepción de algunas piezas de sillería, posiblemente en posición secundaria y quizá correspondientes con las llamadas Pesquerías de los Infantes, los únicos elementos localizados que reflejan una intervención antrópica en el cauce del río son los restos de encachado que recorren su margen derecha, donde se encuentra la Casa del Pulimento, en un tramo del río que se inicia a $280 \mathrm{~m}$ aguas arriba de la edificación y finaliza aguas abajo de la Casa.

Sin embargo, gracias a los modelos LIDAR se ha podido comprobar que en ese punto en el que se inician los encachados y en el que además el río se encuentra ligeramente encajado (lo que facilitaría el embalsado para una posible captación), se observan ciertos indicios que podrían estar reflejando la captación de agua y el recorrido del caz. Este canal tendría un trazado similar al de la cerca actual que delimita los prados de ribera y se dirigiría con una pendiente media del $1,5 \%$ a las inmediaciones de la Casa del Pulimento donde presumiblemente se encontraría una balsa reguladora (Figs. 6 y 7 ). 

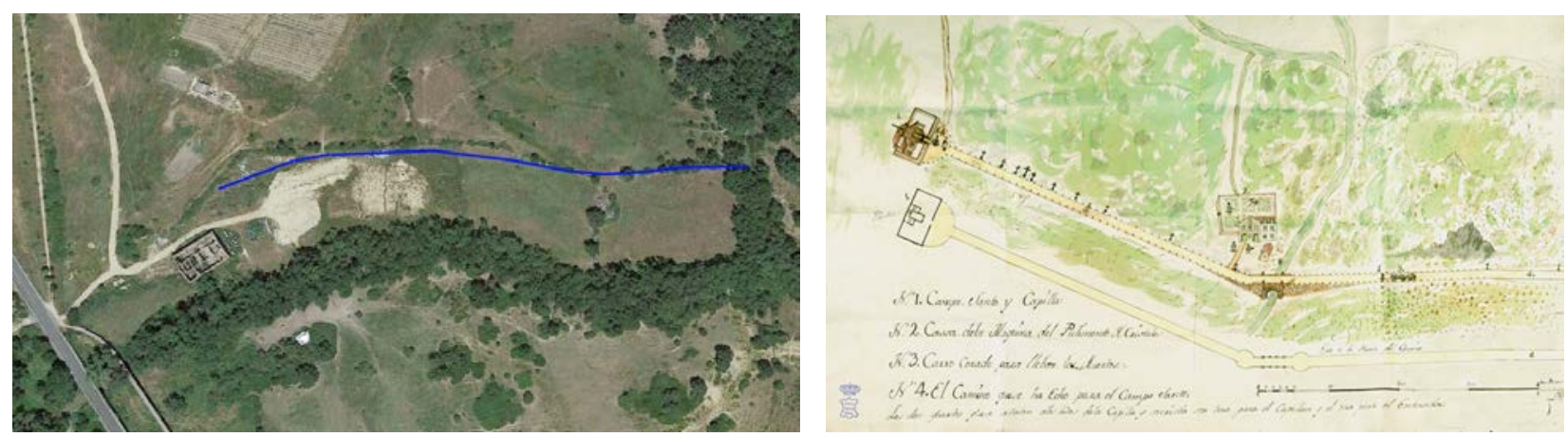

Fuente Fig 7: Alfonso Regalado Rodríguez. Agosto de 1785. AGP. Sección de planos. Sig. 1067

Fig. 6 Posible trazado del canal

Fig. 7 Dibujo del camino que desde el Sitio de San Ildefonso conduce al Cementerio del mismo

La prospección arqueológica de superficie ha permitido documentar también otros elementos patrimoniales ajenos a la Casa del Pulimento como es el caso del puente llamado de la Máquina sobre el río Cambrones, estructura aún en uso que responde a la tipología de los puentes de la segunda mitad del siglo XVIII. Fue construido posiblemente hacia 1785 como parte del acceso cementerio de La Granja recién construido (Sanz de Andrés, 2007), como parece avalarlo la existencia de un dibujo (Fig. 7) en el que se representa el puente, el camino y el propio cementerio. Es muy posible que este puente se asentara sobre otro anterior, del que en la actualidad no se observan huellas, que daría servicio a la Casa del Pulimento.

\subsection{Estudio documental}

Por decisión del ministro de Hacienda, marqués de Esquilache, y recomendación del director de la Real Fábrica, Bernardo Ward, llega a San Ildefonso el ingeniero irlandés Juan Dowling en el año de 1761. Su misión era construir una nueva máquina hidráulica de pulir vidrio plano para la fabricación de espejos que se pensaba instalar a orillas del arroyo Cambrones, próximo al Real Sitio.

Según la documentación consultada, en mayo de 1762 ya se habían empezado a construir los cimientos de la Casa de la Máquina, pues el director Bernardo Ward da orden para que el Aparejador del Real Sitio D. Miguel Núñez examine y reconozca los materiales, cimientos y grueso de las paredes para comprobar la solidez del edificio. El Maestro de Obras encargado de construir la casa, máquina, presa y canal fue Antonio Niño.

Miguel Núñez figura en estos años como Aparejador del Real Sitio de San Ildefonso, trabajando en la construcción del palacio de Riofrío. Según Juan Francisco Hernando Cordero "fue uno de los personajes más importantes de la corte de la "Reina Viuda" llegando a acaparar numerosos títulos".

En La Granja, como vimos, se le encarga el proyecto de la Casa del Pulimento y en 1763 recibe el encargo para la construcción de la iglesia de Ntra. Sra. de los Dolores.

Antonio Niño fue el maestro de obras contratado para la ejecución de los trabajos de la Casa del Pulimento, máquina, presa y canal, un maestro de reconocido prestigio también en San Ildefonso, donde también participa en la construcción del Cuartel de Guardias de Corps.

No sabemos en qué fecha llegó Juan Dowling a España procedente de Irlanda. En el año 1755 trabajaba en la Real Fábrica de Paños de Brihuega. En septiembre de 1763 el rey le había nombrado Ingeniero Hidráulico de las Fábricas del Reino, por su capacidad y celo en la construcción de la máquina de pulir, con destino a las de cristales del Real Sitio y administrador de la misma.

Además de la Fábrica de Acero y Limas y la Máquina del Pulimento de San Ildefonso, su actividad fue muy intensa, pues él mismo escribió en varias ocasiones el desconocimiento de la materia en nuestro país y la falta de mano de obra especializada. Trabajó también en la Fábrica de Paños de Brihuega, de Espadas de Toledo, Aranjuez, Fábrica de Latón 
de Alcaraz, Departamento de Marina de El Ferrol, Fábrica de Tejidos de Seda, Oro y Plata de Talavera, Nuevos Cuarteles de El Escorial y Madrid.

Además de toda esta labor, fue nombrado Académico en la Junta Ordinaria del 5 de octubre de 1766. Algunos de sus dibujos fueron remitidos a la Academia, directamente por manos del rey. Entre dichos dibujos existen varios relativos a la Casa del Pulimento de San Ildefonso de los que hablaremos más adelante

Los trabajos para la construcción de la Casa y Máquina del Pulimento en San Ildefonso comenzaron el 11 de mayo de 1762 .

No conservamos los dibujos originales de Miguel Núñez, pero es posible que Dowling los utilizara para los diseños que envió en 1767 a la Academia de San Fernando, un año después de su nombramiento como académico, en los cuales dibuja la planta y dos secciones del edificio, además de la máquina para el pulimento de cristales.

Contamos también con un dibujo y un grabado realizados con motivo de la construcción del Cementerio algunos años después (Fig. 7).

Los enciclopedistas franceses, Diderot y D'Alembert dibujaron los alzados y planta de esta máquina (Fig. 2) con escrupuloso detalle, lo que demuestra que se trataba efectivamente de un novedoso ingenio para la época. Es posible que para estos dibujos se utilizaran también los planos originales de Miguel Núñez y de Dowling (Fig. 8).

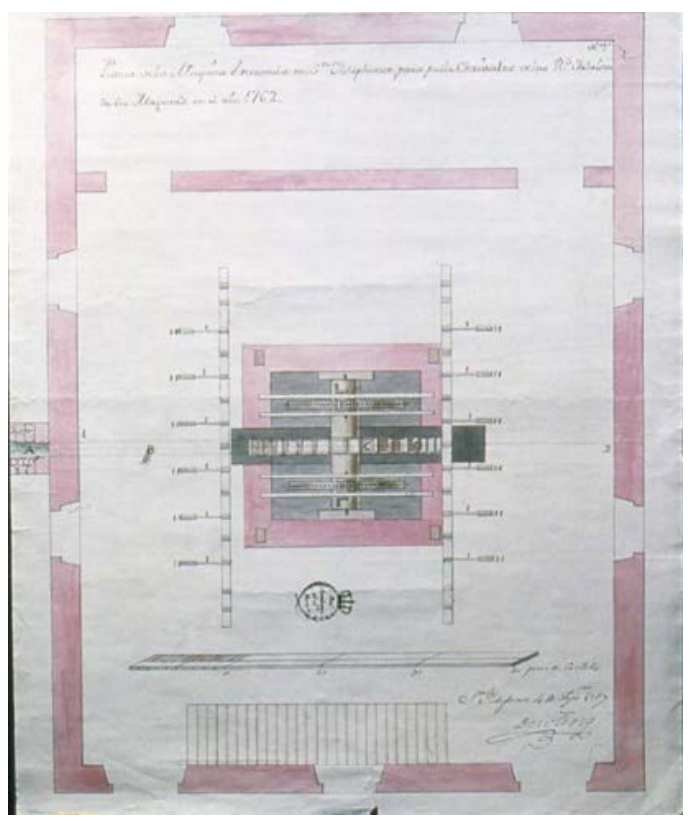

Fig. 8 Planos. Copia de una máquina para pulir cristales de la Real Fábrica de San Ildefonso construida en 1762. Dibujo, fechado, firmado y rubricado en San Ildefonso, 4 de septiembre de 1767. Dowling. A-5236, planta. A- 5238 alzado

No sabemos en qué momento se derribaron la segunda planta y las buhardillas, pero de lo que no cabe ninguna duda es que todos los dibujos conservados muestran la existencia de las mismas desde su construcción.

La máquina de Dowling a orillas del arroyo Cambrones funcionó hasta principios del siglo XIX. Su lejanía, la incomodidad que resultaba del constante trasiego de lunas desde San Ildefonso a la Casa de la Máquina para ser pulidas y el consiguiente riesgo de roturas, la servidumbre que suponía el tener un vigilante permanente para evitar robos y vigilar las crecidas de lluvias, el trasiego constante de pulidores y peones que se tenían que desplazar desde el Real Sitio, el deterioro de la rueda como consecuencia de sus largos años de funcionamiento, todas éstas fueron las causas principales que obligaron a trasladar la máquina del pulimento al edificio donde se encontraba la antigua de Sit y Frontvilla, es decir, detrás de la Iglesia de los Dolores. 
Un documento indirecto revela que en 1801 se encontraba en desuso y que en 1820 estaba en estado de ruina, situación en la que permaneció gran parte del siglo XIX, mientras que, como el resto de las instalaciones pertenecientes a la Real Fábrica de Cristales, pertenecía a la Corona. En 1870, en virtud de las leyes desamortizadoras de los bienes pertenecientes a la Corona, la finca del Pulimento sale a subasta pública. El expediente de oferta pública tiene una somera descripción del inmueble (Boletín, 1870) que pone de manifiesto que el edificio se encontraba arruinado y que había perdido la concesión de aguas procedentes del río Cambrones. Aunque se desconoce a qué uso se dedicó en los años posteriores a su venta, lo cierto es que no debió de mejorar su estado de conservación ya que en 1891, su segundo propietario, Guillermo Maderuelo, acotó la propiedad y reedificó la construcción, como lo refleja la inscripción en el cargadero sobre el acceso principal. La intervención en el edificio, aunque debió de resperar los muros perimetrales, fue de considerable envergadura para adaptarlo a encerradero de ganado, función que se ha mantenido durante todo el siglo XX. Desde entonces y hasta el año 2003 la finca ha pertenecido a los sucesivos herederos de la familia Maderuelo hasta que en el año 2003 fue vendida a una empresa inmobiliaria que ha mantenido la propiedad sin uso hasta que en el año 2007 volvió a manos públicas a través de una cesión de la firma propietaria al Ayuntamiento de San Ildefonso.

\section{Consideraciones finales}

Los resultados de los estudios previos que se han expuesto sucintamente en esta comunicación ponen de manifiesto la relevancia de la Casa del Pulimento en relación, no solo con la historia de la Real Fábrica de Cristales de La Granja y con la de la ingeniería, sino también con la del propio municipio de La Granja de San Ildefonso, como un bien patrimonial que forma parte de su identidad. Pero para alcanzar el propósito de su recuperación y difusión, resulta necesaria la continuidad del proyecto con acciones que permitan tanto la conservación de sus testimonios materiales, como la recuperación de su memoria, hasta ahora perdida.

\section{Referencias}

Boletín Oficial de Ventas de Bienes Nacionales. (1870). Boletín Oficial de Ventas de Bienes Nacionales. Provincia de Segovia, $\mathrm{n}^{\circ} 27$, 19 de octubre.

Diderot, M., y Dálembert, M. (1765). Encyclopédie ou dictionnaire raisonné des sciences, des arts et des métiers, París, vol. IV (Glaces).

Juárez Valero, E. (2016). Ingenieros e ingenios en la Real Fábrica de Cristales. En A. Cámara y B. Revuelta (Eds.), Libros, caminos y dias (pp. 125-137). Madrid: Fundación Juanelo Turriano.

Pastor Rey de Viñas, P. (1994). Historia de la Real Fábrica de Cristales de San Ildefonso durante la época de la Ilustración (17271810). Madrid: Fundación Centro Nacional del Vidrio, CSIC.

Pastor Rey de Viñas, P. (1998). Vestiges archéologique du XVIII siècle découverts en 1995 dans la Manufacture de La Granja. En Association Française pour l'Archéologie du Verre. XI Recontres. De la Verrerie forestière la verrerie industrielle, du XVIII siècle aux années 1920. Encuentro llevado a cabo en Albi, 1996. Francia: Edit. Aix-en-Provence.

Pastor Rey de Viñas, P. (1997). Restos arqueológicos hallados en la Sala del Raspamento de la Real Fábrica de Cristales de La Granja. En S. Torreguitart (Ed.), Actas de las Jornadas sobre el Real Sitio de San Fernando y la industria en el siglo XVII (pp. 219-230). San Fernando de Henares: Ayuntamiento de San Fernando de Henares.

Pastor Rey de Viñas, P. (2004). Real Fábrica de Cristales. En M. P. Soler y J. R. Aparicio (Eds.), El entorno de Segovia en la historia de la dinastía de Borbón (pp. 65-80). Madrid: Ministerio de Educación, Cultura y Deporte.

Ruiz Hernando, A., y Callejo Delgado, M. J. (1988). Las Fábricas de Vidrio de La Granja. Estudio arquitectónico. En Vidrio de La Granja (pp. 33-55). Madrid: Ministerio de Cultura.

Sanz de Andrés, M. (2007). El cementerio del Real Sitio de San Ildefonso en la Corte Ilustrada de Carlos III. Estudios Segovianos, L, 107, 511-601.

Soler, J. (2014). Patrimonio industrial en Segovia. Huellas de la antigua industria. Segovia: Real Academia de Historia y Arte de San Quirce. 